\title{
Manufacturing strategy frameworks suitable for SMEs
}

\section{Malin Löfving}

Department of Industrial Engineering and Management,

School of Engineering, Jönköping University, Jönköping,

Sweden and

Department of Technology Management and Economics,

Chalmers University of Technology, Göteborg, Sweden

Kristina Säfsten

Department of Industrial Engineering and Management,

School of Engineering, Jönköping University, Jönköping, Sweden, and

Mats Winroth

Department of Technology Management and Economics,

Chalmers University of Technology, Göteborg, Sweden

\begin{abstract}
:
Purpose: The paper aims at increasing the understanding of how manufacturing strategy formulation can be facilitated in SMEs.

Design/methodology/approach: The research presented in this paper follows a four-stage logic. Initially a literature review was conducted identifying a number of manufacturing strategy frameworks. Thereafter, theoretical and practical assessment criteria were established. The SME requirements were identified through five case studies. Based on these assessment criteria, identified manufacturing strategy formulation frameworks were evaluated. When a framework was found that fulfilled most of the requirements set out, a detailed analysis of the framework was done, based on criteria related to specific SME characteristics.
\end{abstract}

Findings: In total 15 different manufacturing strategy formulation frameworks were identified in the literature. To evaluate the suitability of these frameworks in SMEs, a number of assessment criteria were established, both in theory and in practice. These assessment criteria were grouped into three parts based on their character: procedure, realisation and contextual issues. The assessment of the 15 frameworks revealed that among the identified frameworks there was one framework that stood out and fulfilled several of the criteria. However, the frameworks still need to be adapted to the specific SME characteristics.

Practical implications: Based on an assessment of the existing manufacturing strategy frameworks we have been able to identify one framework that fulfills 10 out of 14 of the theoretical and empirical requirements.

Originality/contribution: Although a number of manufacturing strategy frameworks exist, their applicability in practice has seldom been investigated. The results presented provide valuable knowledge for the continued work of rendering manufacturing strategy frameworks suitable and thereby useful for SMEs. 
Keywords: manufacturing strategy, formulation process, strategy frameworks, assessment, applicability, SME

\section{Article Classification: Research paper}

The project is financially supported by the Swedish Agency for Innovation Systems (VINNOVA) and Agency for Science, Technology and Research (A*STAR) in Singapore. The authors owe deep gratitude to the five companies that participated in this study. This study is also supported by Chalmers Area of Advance on Sustainable Production and its Sustainable Production Initiative. The authors would like to thank the two anonymous reviewers for their valuable suggestions and comments to improve the quality of this article.

\section{Introduction}

Small and medium-sized enterprises (SMEs) play a significant role in the economy and serve as an engine in economic growth (European Commission, 2007). In an era of globalisation, rapid technology changes (Hitt et al., 2007) and increased competitiveness, SMEs must survive and maintain their competitiveness in the market place (Laforet and Tann, 2006). For SMEs, manufacturing is often a core competence (Cagliano and Spina, 2002). Manufacturing can be a competitive advantage if the right decisions are made that support the order winners (Größler, 2007; Hill and Hill, 2009). This can be captured in a manufacturing strategy. In the area of manufacturing strategy it is common to distinguish between content, i.e. what a strategy consists of, and process, i.e. how a strategy is formulated and implemented (Voss, 1995; Papke-Shields et al., 2006). During the last two decades, much research has focused on the content of manufacturing strategies and less effort has been put on actually understanding the process (Dangayach and Deshmukh, 2001; Rytter et al., 2007). Even though there is a large potential in manufacturing SMEs, the number of studies are rather limited. Some studies focus on strategy in manufacturing SMEs (e.g. O'Regan and Ghobadian, 2006; Raymond and Croteau, 2006; Ates, 2008; Bellamy, 2009), other mention manufacturing strategy together with business strategy and other functional strategies (e.g. Bell et al., 2004; Galbraith et al., 2008), and a few studies focus on manufacturing strategy in SMEs (Barad and Gien, 2001; Barnes, 2000; 2002a; 200b2; Säfsten and Winroth, 2002). As a strategy process is quite complex and competence in this area often is often limited regarding SMEs (Barnes, 2002a; Gibbons and O'Connor, 2005), there is a need for a deeper understanding. Commonly the literature describes manufacturing strategy formulation through structured frameworks, processes, procedures, models and methodologies (Lindström, 2008). In this paper, the concept of manufacturing strategy framework is used to signify any kind of structure or procedure that supports strategy formulation.

There is a great potential for SMEs to use manufacturing strategies in a manner that contributes to sustainable competitiveness in their market place (Hudson et al., 2001). This requires knowledge of the conditions among SMEs concerning manufacturing strategy formulation and the requirements on strategy frameworks for them to be useful. Another relevant question is whether manufacturing strategy frameworks really reflect practice (Leong et al., 1990). This paper aims at increasing the understanding of how manufacturing strategy formulation can be facilitated in SMEs. The following research questions are addressed:

- What do SMEs require from a framework to support manufacturing strategy work?

- Are existing manufacturing strategy frameworks suitable for SMEs? 
The remainder of this paper is structured as follows. The next section addresses research on manufacturing strategy formulation and especially the current situation in SMEs. Thereafter the research design is presented, followed by the empirical results concerning what SMEs require from a strategy frameworks/tools. Then the identified manufacturing strategy formulation frameworks are assessed based on empirically and theoretically established criteria in 5 practical cases. Then a 'best' framework is identified. Finally, the paper ends with a discussion, conclusions and practical implications.

\section{Theoretical framework}

SME characteristics

There is no single universal definition of what constitutes a small and medium-sized enterprise (Carter and Jones-Evans, 2006). The most common definition in Europe is the quantitative definition provided by the European Commission (2005), including number of employees, turnover and/or balance sheet. Recently the European Commission also included independence in its definition. To be considered independent, not more than 25 per cent of the company should be owned by another company (European Commission, 2005). However, according to Säfsten and Winroth (2011, p.4), "a small unit within a large international company group could very well face the same problems as an independent company". More interesting than formal definitions are, however, the characteristics that render SMEs special. Previous studies have pointed out key characteristics of small and medium-sized enterprises (e.g. Robinson and Pearce, 1984, Ghobadian and Gallear, 1997; Hudson et al., 2001, Marsden and Forbes, 2003):

- personalised management,

- severe resource limitations in terms of management and manpower, as well as finance,

- reliance on a small number of customers and operation on limited markets,

- a high innovative potential,

- a reactive, fire-fighting mentality,

- informal, dynamic strategies,

- a flat and flexible organisation.

Several of these characteristics can be assumed to affect the conditions required for how to work with manufacturing strategies (Ghobadian and Gallear, 1997; Yusof and Aspinwall, 2000).

\section{Manufacturing strategy formulation in SMEs}

Most research on manufacturing strategy formulation has either focused on prescriptive frameworks providing support when developing manufacturing strategies (Skinner, 1969; Hayes and Wheelwright, 1984; Hill, 1989; Miltenburg, 2005) or descriptive case studies (Marucheck et al., 1990; Persson, 1991; Swamidass et al., 2001; Pun et al., 2004; PapkeShields et al., 2006; Kiridena et al., 2009), mainly in larger companies. Manufacturing strategy formation in SMEs is a more or less ignored area (Barnes, 2000) and is still not well understood. Based on case studies in six small manufacturing companies in the UK, Barnes (2002a, 2002b) concludes that manufacturing strategies in SMEs evolve through a bottom-up emergent process rather than a top-down planning process, which also are showed in research studies on strategy SMEs (Marsden and Forbes, 2003; Wiesner and Millett, 2012). According 
to Cagliano et al. (2001, p. 470) strategies in SMEs "emerge through incremental learning processes and tactical decisions, which are aimed at acquiring critical resources and building distinctive capabilities that are valued by customers, rather than being crafted through formal long-term planning processes". The strategy formulation in SMEs is unique, it bears little resemblance with the strategy process in larger organisations (Jennings and Beaver, 1997) and formal strategy formulation is rare (Robinson and Pearce, 1984; Ates, 2008). Reasons given for this are lack of time, resources and flexibility, as well as experiences and knowledge of the owner-manager/CEO and informal decision making (Robinson and Pearce, 1984; Cagliano and Spina, 2002; Marden and Forbes, 2003; Carter and Jones-Evans, 2006; Ates, 2008). There are only a few studies on the use of manufacturing strategy formulation frameworks in SMEs (e.g. Säfsten and Winroth, 2002). Research indicates that existing frameworks are too complex or require too much time to be frequently accepted by SMEs (Robinson and Pearce, 1984; Säfsten and Winroth, 2002; Bellamy, 2009). It is also advocated that the formulation process in SMEs should be informal and incorporate several participants, both internal and external (Robinson and Pearce, 1984). Due to these findings, it is essential that properties of manufacturing strategy formulation frameworks suitable for SMEs are identified.

Modern manufacturing strategy formulation has evolved from two broad schools, both originating from the business strategy area (Robinson and Pearce, 1984; Platts, 1994; Jennings and Beaver, 1997; Verreynne, 2006). The predominant view of manufacturing strategy formulation is the prescriptive rational planning view based on the works by Skinner (1969) and Wheelwright (1978). According to this school, strategies are intentionally defined in a formal, rational and systematic manner to establish action plans (Platts, 1990). Prescriptive formulation frameworks consist of well-defined steps involving, for example, gap analysis, SWOT analysis, customer and competitor analysis, as well as a definition of objectives (Platts, 1990; Ates, 2008). Within this school, business strategy drives manufacturing strategy, i.e. it occurs top-down (Platts et al., 1996). This view has been criticised for being too rational, not operationalising the strategies and not considering how strategy is really being formed (e.g. Barnes, 2000; Rytter et al., 2007). According to the other school, strategic work is more intuitive and creative and strategies are formed incrementally in iterative small steps (Quinn, 1978; de Wit and Meyer, 2010). Descriptive research studies, for example, try to understand the decision-making process in which the process is a dialogue and actions are iterative (Rytter et al., 2007). According to this school, manufacturing strategy is not a fixed plan and emerges rather than being planned (Platts, 994). Bellamy (2009, p. 545) concludes: "the success of SMEs would probably not be enhanced by forcing them to act like a large company and go through prescriptive strategy formulation processes, as it is incongruent with their resources". This was confirmed by Yusof and Aspinwall (2000) and by Harris, Forbes and Fletcher (2003), who concluded that prescriptive frameworks are not suitable for SMEs. Since many manufacturing strategy formulation frameworks are prescriptive, this can be a factor that affects the use of manufacturing strategies in SMEs.

\section{Assessment criteria}

To identify a suitable manufacturing strategy formulation framework for SMEs, a review and assessment of the existing frameworks is needed. There has been some work done evaluating the actual manufacturing strategy and, for instance, its consistency (Hayes and 
Wheelwright, 1984; Slack, 1995). However, this paper focuses on manufacturing strategy formulation, not the resulting manufacturing strategy. We are looking for characteristics of successful strategy formulation frameworks and the assessment criteria derived from the literature review. Based on case studies involving companies that had recently completed reassessment of their manufacturing strategies, Platts (1994) identified four groups of characteristics of methodologies used successfully in the formulation of strategies: procedure, participation, project management and point of entry. Many of the characteristics focus on the way of working and on more organisational aspects, and less focus is on what a framework includes. Platts's (1994) characteristics resemble each other and are therefore merged into two groups: procedure and realisation.

We defined procedure in accordance with Platts (1994), as there should be well-defined procedures, visual tools and written documents in each step. The steps in a process should be well defined in the following stages (Platts, 1990): gathering of information, analysing information and identifying improvements. Visual representation in decision-making is widely researched (e.g. Platts et al., 1996; Platts and Tan, 2004); it simplifies the understanding and the use of a framework. Visualisation is made by tools, techniques, and worksheets. Worksheets are written documents that enable accessibility of data, papers and decisions to the participants (Platts, 1994). Adam and Swamidass (1989) used infrastructure, manufacturing task and order winning criteria as process variables, here called competitive priorities and decision areas. It is essential that both intangible and tangible competitive priorities are included in a framework (Platts et al., 1998). As the competitive priorities constitute an operation's interpretation of market requirements and customer demands, a company must analyse both customers and competitors (Miltenburg, 2005).

Realisation of a manufacturing strategy process concerns both managerial and organisational issues, such as participation, communication, project management and point of entry. Hence, the suggested characteristic, realisation, includes three of the former groups as defined by Platts (1994). Traditionally, manufacturing strategies were formulated by top management (e.g. Skinner, 1969; Platts, 1990). Thus, it is well known that the key mechanism for overcoming resistance to change is to include employees and allow them to participate in the formulation (Coch and French, 1948; Slack and Lewis, 2002; Riis et al., 2006). As participation and resourcing cannot be neglected in a review, this is called adequate resource identification, i.e. who is responsible and who participates in the formulation (Platts, 1990). Platts (1994) points out the importance of both individual and group participation for achieving enthusiasm, understanding and commitment. For group participation there should be a decision-making forum and workshop-style meetings to agree on objectives, identify problems and develop improvements (Platts, 1994). An agreed timescale is another criterion (Platts, 1990; Baines et al., 2005). The time scale sets the limits when the project should end and defines the plan on what to do. However, there should also be clearly defined objectives and expectations of the resulting strategy and of the process (Platts, 1990).

Additionally, contextual issues such as internal and external factors also affect the use of a framework (Pettigrew et al., 1998). The contextual issues include in what country the framework is developed, company size range, and whether it is conceptual or based on empirical tests (Barnes, 2002a, 2002b; Sum et. al., 2004; Rytter et al., 2007). In 
manufacturing strategy literature, the predominant view of competition is market-based but gradually developing into a resource-based view (Dangayach and Desmukh, 2001). The research on the manufacturing strategy process in SMEs disagrees on what view SMEs actually have, probably depending on case companies and industries (Barnes, 2002a; Ates and Bitici, 2009). Barnes (2002b) discussed the complexity of the manufacturing strategy process and stated that operation management researchers cannot only see frameworks as onedimensional, only using one of these views. Table I summarises the assessment criteria identified in the manufacturing strategy formulation literature.

Insert Table I here.

Table I. Theoretically derived criteria for assessment of manufacturing strategy formulation frameworks.

\section{Research methodology}

The results presented in this paper follow a four-stage logic. First a literature review was conducted identifying the manufacturing strategy frameworks. Second, assessment criteria were established from theory and case studies. Third, identified manufacturing strategy formulation frameworks were assessed based on the assessment criteria. Finally, when a framework was identified that fulfilled most of the requirements set out; a specific analysis of the framework was done, based on criteria related to SMEs.

During the first stage, the literature review, a number of databases were selected to cover a diverse range of publications (e.g. journal articles, books and dissertations). The databases include Scopus, Science Direct and ABI/Inform. Keywords included manufacturing (operations) strategy framework, formulation, SME, methodologies and process. When relevant publications were found, references and citations were crosschecked to capture additional publications. The literature review covers publications between 1969 (to include Skinner's model) to 2012, and a number of publications were identified (excluding results solely focused on implementation or deployment of frameworks). Finally, 15 publications containing a description of a manufacturing strategy framework were identified.

During the second stage, a literature review was conducted to identify assessment criteria for manufacturing strategy frameworks in theory. In this literature review the same strategy and databases were used as in the first review, but the keywords also included evaluation, testing and assessment. During the practical part of stage two, the requirements that SMEs have on a manufacturing strategy framework were identified through five case studies. The case studies represented five manufacturing companies, hereafter labelled Company Automotive, Company Aluminium, Company Casting, Company Outdoor, and Company Plastics, see Table II for an overview of the companies involved. Data were collected by means of a series of semi-structured interviews with 31 key respondents (Yin, 2009). The respondents included owners, managing director, production manager, sales responsible, production engineer, engineering designer, quality manager, etc. (Säfsten and Winroth, 2011). The respondents were asked about their requirements on a manufacturing strategy formulation framework. 
After the interviews, the case companies have formulated their own manufacturing strategies. During this process, the researchers have had regular meeting with the case companies and participated as observers at meetings.

Insert Table II here.

Table II. Case company characteristics

During the third stage of the research, each framework was assessed based on the empirical and theoretical assessment criteria shown in Table IV. When a framework fulfilled an assessment criterion, it was marked with 'yes' or another relevant indicator. For each framework the frequency of fulfillment of empirical and theoretical assessment criteria was compiled. One of the frameworks met more of the empirical requirements than the others, and this was chosen as the most suitable framework for SMEs. As a fourth and final stage, this framework was further analysed with criteria for successful strategic planning in SMEs (Robinson and Pearce, 1984), based on SME characteristics.

\section{What a manufacturing strategy framework require in practice}

\section{Procedure}

All of the case companies mentioned that a framework needs to be simple and most of them that it has to be easy to understand and to use. Easiness was, for example, described as including specific steps and being simple that the framework should consist of a limited number of steps. The companies emphasised that a framework has to be visual, since strategy formulation concerns many different functions and roles within a company. Although the companies agreed that possibilities for visualisation were important, they disagreed on the visualisation tools. The different visualisation tools mentioned include paper, whiteboards and software programs. Company Casting preferred software programs, whereas Company Automotive and Company Outdoor preferred physical information on paper, since it was regarded as the easiest way to communicate with the manufacturing operators.

\section{Realisation}

Company Automotive, Company Casting and Company Plastics mentioned that a framework should enable an agreed time perspective as the managers lack time and cannot spend too much time on long-term planning, as they are needed at the operational level. All companies mentioned involvement and communication, but in different contexts. Communication concerned how information about the formulation and manufacturing strategies is disseminated. Involvement concerned who were going to participate in the manufacturing strategy formulation. Company Aluminium, Company Automotive and Company Plastics agreed on the importance of involvement of manufacturing operators and Company Outdoor also mentioned involvement from other functions. The function managers at Company Automotive and Company Aluminium participated in the formulation of both business strategies and manufacturing strategies. Company Outdoor mentioned that manufacturing strategy formulation needs commitment and involvement from the management. Company Outdoor explicitly said that they preferred to work in teams.

\section{Contextual issues}

As described earlier, clear objectives and expectations were identified as requirements. In addition to this, someone at Company Casting explicitly said, "I want to learn something from 
the process". This is a clear expectation and also shows willingness to spend time to learn something from a process.

The empirically identified assessment criteria (Table III) were categorised in the same structure as the assessment criteria identified in the manufacturing strategy formulation literature.

Insert Table III here.

Table III. Empirically derived criteria for assessment of manufacturing strategy formulation frameworks

\section{Assessment of manufacturing strategy framework}

The result from the assessment is presented in Table IV. There is an inconsistency between the two parts procedure and realisation. A majority of the identified assessment criteria belong to the procedure part. In one third of the frameworks, none of the realisation part criteria were included (Fine and Hax, 1985; Kim and Arnold, 1996; Gilgeous and Gilgeous, 1999; Slack and Lewis, 2002; Jia and Bai, 2011). Hence a vast majority of the frameworks include welldefined steps as well as competitive priorities and decision categories, as shown in Table IV. Although the frameworks have been developed separately, most of them have clearly been affected by the prescriptive tradition that exists in manufacturing strategy research (e.g. Skinner, 1969; Wheelwright, 1978; Fine and Hax, 1985; Hill, 1989; Kim and Arnold, 1996) focusing on the procedure part.

\section{Procedure}

The case companies mentioned that a framework should be simple and easy to use and understand. However, only a few frameworks are simple and easy to understand, based on the fact that they comprise a limited number of defined steps and pictures (Wheelwright, 1978; Kim and Arnold, 1996, Slack and Lewis, 2002). A number of frameworks are neither simple nor difficult to understand (Hill, 1989; Crowe and Cheng, 1996; Baines et al., 2005; Jia and Bai, 2011). These are labelled average simplicity (avg) in Table IV, as they consist of many steps or the description that exists is too vague in describing how to use the frameworks.

Only a few frameworks describe tools and techniques for visibility. Platts and Gregory (1990) and Baines et al. (2005) mentioned worksheets and workbooks, and Karacapilidis et al. (2006) used software programs. The case companies did not agree on what tools/techniques to use. Some of them preferred software programs and some preferred papers. Thus, a tool that can be used both as software and on paper is preferable. A framework should be visual; whether on paper, on whiteboards or as software programs is irrelevant as long as it is communicated to manufacturing operations through the same channels as other information.

Insert Table IV here.

Table IV. Assessment of manufacturing strategy framework

\section{Realisation}

The most commonly fulfilled realisation criterion was participation (mentioned in 9 out of 15 frameworks). This requirement originates from Skinner (1969) and Wheelwright (1978) and many frameworks are inspired by these two. In general, there is a lack of descriptions of 
issues related to the realisation part in the frameworks (Adam and Swamidass, 1989; Rytter et al., 2007). Riis and Johansen's $(2001,2003)$ manufacturing vision stands out as they have quite good coverage in the realisation part (6 out of 8).

The case companies stated that communication with manufacturing operators was necessary, but none of the frameworks mentions communication at all. However, some frameworks describe involvement (Skinner, 1969; Hill, 1989; Mills et al., 1995; Riis and Johansen, 2001; 2003; Baines et al., 2005), but only Skinner (1969) and Riis and Johansen (2001, 2003) mention involvement of manufacturing employees. Riis and Johansen (2003, p. 328) state that: "[p] eople in the organisation should be engaged and motivated as everybody should have a shared view of the future". Baines et al. (2005) do have a list of people involved in the strategic decision process as supply and logistics experts.

Agreed time scales in the manufacturing strategy formulation process are important to SMEs, as they lack time and their focus is on solving daily problems. Four frameworks describe time scales (Wheelwright, 1978; Mills et al., 1995; Riis and Johansen, 2003; Baines et al., 2005), of which Riis and Johansen's (2003) manufacturing vision requires the longest time, three to five months with one-day seminars. In Wheelwright's (1978) framework, each company decides on how long the process will take, and Baines et al. (2005) estimate the time at two to three weeks. Mills et al. (1995) mention that strategy creation should be an ongoing process, but they do not define time frames further. Miltenburg's (2005) framework has been tested at two SMEs and the time needed to perform the analysis was estimated at three days (Säfsten and Winroth, 2002).

\section{Contextual issues}

As presumed in the literature (Barnes, 2002b), empirical tests of frameworks are often done in large companies, but recently frameworks have been tested in SMEs (Riis and Johansen, 2001,2003; Baines et al., 2005; Jia and Bai, 2011). Most of the identified frameworks are tested empirically and the original papers describing the frameworks also contain descriptions of this. There were, however, only a few publications containing descriptions of empirical use or further tests of frameworks (e.g. Persson, 1991; Gilgeous and Gilgeous, 2001; Säfsten and Winroth, 2002; Lim et al., 2006), so questions about the practical use of frameworks remain.

One case company mentioned organisational learning as an important output from a strategy process and that importance has been stated by other authors (Adam and Swamidass, 1989; Rytter et al., 2007). Among other researchers, only Riis and Johansen (2001, 2003), Karacapilidis et al. (2006) and Kim and Arnold (1996) adopt this view.

The framework that fulfils most empirical requirements (10 of 14) is Riis and Johansen's (2001, 2003) manufacturing vision. This framework has gone through a deeper analysis according to Robinson and Pearce's (1984) criteria for the strategic planning process in SMEs: not being complex, having a time horizon, implementing an informal process and incorporating several participants. Riis and Johansen's manufacturing vision has few steps, but the description of what to do in each step is vague in the existing description (Riis and Johansen, 2001, 2003). The manufacturing vision aims at getting a shared organisational picture of future manufacturing, i.e. a longer time horizon than the two years recommended by Robinson and Pearce (1984). In the manufacturing vision there are steps that should be followed and it takes a long time and many workshops to develop a manufacturing vision in a 
company. The nature of capturing ideas and knowledge about the current situation can be interpreted as informal. The last criterion from Robinson and Pearce (1984) was that the process should incorporate several participants, both internal and external, which the manufacturing vision does. Both managers and employees are involved as the framework is grounded on a collaborative dialogue. Each company decides the number of participants; however Riis and Johansen (2003) describe groups consisting of 20 people, which is not possible in SMEs. The manufacturing vision can be applicable to SMEs according to Robinson and Pearce's (1984) criteria since it consists of few steps, involves collaboration and is quite informal. This framework has the potential to be a suitable framework for SMEs. To get a deeper insight into this framework, more descriptions and instructions are needed. Further tests (and refinements) of the frameworks are also needed in SMEs.

\section{Discussion}

All case companies requested a simple and easy-to-use framework, which is in line with several other research studies (Robinson and Pearce, 1984; Yusof and Aspinwall, 2000; Säfsten and Winroth, 2002; Bellamy, 2009). Still there is no framework that is both simple and easy to use and fulfils a majority of the empirical requirements. Riis and Johansen's (2001) manufacturing vision is comprehensive as it meets most of the empirical requirements. On the other hand, the simplest framework is that of Slack and Lewis (2002) consisting of a matrix including competitive priorities and decision categories. However, Slack and Lewis do not fulfil many of the other empirical requirements (only 2 out of 14), as there are no instructions and descriptions of how to formulate a manufacturing strategy. This assessment has not weighted the different assessment criteria and the case companies did not weight their requirements. To really understand what SMEs require of a manufacturing strategy framework, the empirical requirements should be weighted. If weighted, the most important assessment criteria for SMEs could be emphasised. Had the criteria been weighted on our assessment it is not clear that the result would have been the same.

The assessment criteria were identified from the manufacturing strategy process area. Much of the theory in this area is based on research in larger companies and SMEs are not well understood. However, there is research about general strategy processes (e.g. Robinson and Pearce, 1984) and quality management in SMEs (e.g. Yusof and Aspinwall, 2000) that can be applicable to get knowledge about what SMEs require of a framework in their strategy formulation processes. On the other hand, the research about strategy in SMEs are increasing and so frameworks for strategy making for entrepreneurs and SMEs (for example Osterwalder and Pigneur, 2010). As the business strategy, and manufacturing strategy are closely related, the study could be extended to also reviewing strategy frameworks for SME to analyse if frameworks for formulation of business strategy also includes formulation of manufacturing strategies. However, to really understand the formulation process and the suitability of frameworks in SMEs, more case studies are needed to test and evaluate the use of various frameworks in practice.

The assessment was done based on the identified descriptions of the frameworks. Further descriptions of the frameworks may exist that are not included in the paper. Some frameworks are presented in books while others are described in papers. The frameworks presented in books include a more extensive description of how to formulate a manufacturing strategy than the frameworks described in papers. The frameworks in books focus more on practitioners 
than researchers, which can make them more accessible and better understood in industry. Some of them are even used in undergraduate courses at universities (Hill, 1989; Slack and Lewis, 2002; Miltenburg, 2005), which makes them accessible to future operations managers. However, as this analysis shows, it is not known whether these frameworks are the most suitable ones for SMEs. Frameworks presented in one or more papers have other researchers as their main readers and the purpose is to present the framework, not to give comprehensive instructions on how to use it.

There is limited research on the use and suitability of manufacturing strategy frameworks, and only a limited number of existing frameworks are developed or tested at SMEs. A need to understand which of the frameworks suits the requirements of SMEs was identified. The research presented in this paper investigates the suitability of frameworks for SMEs. The statement by Leong et al. (1990) that process models must be tested to determine whether they portray practices is still relevant today as this article shows that most of the existing frameworks are not consistent with SME requirements, i.e. they do not portray the formulation practised by SMEs. Most of the frameworks are perceived as not simple enough and do not fulfil the empirical requirements. As SMEs lack resources and time, they require easy-to-use and simple frameworks that take a minimum of time to learn and use. Moreover, Woods and Joyce (2003) analysed the use of strategic tools in SMEs and found out that fewer owner-manager's had knowledge of (strategic) tools than other managers. According to Woods and Joyce (2003) this can depend on the pragmatic perspective - people develop and sustain their beliefs if they are useful in certain circumstances which can be interpreted as the owner-managers did not have the experience, education or knowledge about strategic tools. This can also be the case about manufacturing strategies in SMEs as the owner-managers and managers did not have knowledge about manufacturing strategies and strategic tools and therefore require simple frameworks.

Riis and Johansen assume that strategy is a linear process, while research studies shows that strategy making process in SMEs is not a linear process, but more emergent and incremental (Quinn, 1978). It should be considered whether SMEs need a comprehensive or less comprehensive frameworks which gives them freedom and space to act according to emergent strategies. As the environment is uncertain and SMEs must be flexible in their markets and in their strategies, a less comprehensive framework can be more desirable for SMEs. Earlier research studies also states that SMEs need more emergent and descriptive frameworks, involving the employees in the formulation process. When formulating manufacturing strategies, involvement of different departments and information to employees is important in order to facilitate formulation as well as implementation. Unfortunately, none of the frameworks assessed managed communication and only a few mentioned involvement of employees. Baines et al. (2005) included a comprehensive list of participants involved in the formulation process. To be more useful, frameworks should include a not or list of who expects to be involved to be able to formulate a more useful and competitive manufacturing strategy. Still most frameworks focus on either procedure or realisation-related issues, depending on the responsible research group and its research focus. Two other frameworks also fulfilled several empirical requirements (Baines et al., 2005, Miltenburg, 2005), but the focus in these manufacturing strategy frameworks was on the procedure. Many of the frameworks are conceptual and theoretical, but to be useful in practice, frameworks need to be 
developed in close collaboration with industry in order to understand their requirements. The aim of the article was to identify one superior manufacturing strategy framework, but many of the identified frameworks includes parts that could suit SMEs. To identify one superior framework is also difficult as SMEs are not a homogenous group and what one company prefers is not always preferred by another company. Riis and Johansen's (2001, 2003) manufacturing vision was the framework that fulfilled most of the empirical requirements, but to be useful it should be further analysed and tested in SMEs, and refinements might be needed to simplify the framework.

\section{Conclusion}

The aim with this paper was to increase the understanding of how manufacturing strategy formulation frameworks are suitable for SMEs. The research also sought to examine the SMEs requirements of a framework to support manufacturing strategy work and to analyse if existing manufacturing strategy frameworks suitable for SMEs. The SME requirements were identified through five case studies at SMEs/smaller production sites managed as SMEs. The case companies requested a simple, visual, and easy-to-use framework. However, the assessment of the 15 identified manufacturing strategy frameworks showed that there is still no manufacturing strategy framework that is both simple to use and that fulfils a majority of the empirical requirements. One superior framework (Riis and Johansen, 2001, 2003) was identified as more suitable for SMEs consisting of both parts from the procedure and realisation part of the assessment criteria.

Still, most manufacturing strategy frameworks are prescriptive and developed for larger companies while SMEs require more descriptive frameworks. There is, however, still a need to adapt the frameworks to the specific SME characteristics to make them really suitable.

The case companies are managed as SMEs and they identified requirements for en a framework for strategic work. Due to contextual factors such as organisational culture, management culture, political issues, etc., other companies may have other requirements, which lead to the choice of other frameworks. Therefore, to this point, the research cannot be generalised. One thing worth mentioning is the fact that the requirements by Swedish case companies and similar requirements by SMEs also have been identified in other areas such as TQM (Yusof and Aspinwall, 2000).

This research points out the need for further research on manufacturing strategy in SMEs and also for further empirical research on manufacturing strategy frameworks. The research project will result in a usable manufacturing strategy tool that will be developed in close collaboration with the case companies and their requirements. This tool will also be tested in other contexts than Swedish SMEs.

\section{Acknowledgement}

The project is financially supported by the Swedish Agency for Innovation Systems (VINNOVA). The results presented in this paper were based on studies carried out at the five companies participating in the project to which we owe deep gratitude. This study is also 
supported by Chalmers Area of Advance on Sustainable Production and its Sustainable Production Initiative.

The authors would like to thank the two anonymous reviewers for their valuable suggestions and comments to improve the quality of this article.

\section{References}

Adam, Jr., E. E. and Swamidass, P. M. (1989), “Assessing operations management from a strategic perspective", Journal of Management, Vol. 15, No. 2, pp. 181-203.

Ates, A. (2008), Strategy Process in Manufacturing SMEs, PhD dissertation, Department of Design, Manufacture and Engineering Management, Universtiy of Strathclyde, Glasgow, UK.

Ates, A. and Bitici, U. (2009), "Strategy management in small to medium-sized enterprises: Evidence from UK manufacturing SMEs", in Proceedings of the 16th Annual EurOMA Conference, Göteborg, Sweden, 14-17 June 2009, pp. XX-XX.

Baines, T., Kay, G., Adesola, S. and Higson, M. (2005), "Strategic positioning: an integrated decision process for manufacturers", International Journal of Operations \& Production Management, Vol. 25, No. 2, pp. 180-201.

Barad, M. and Gien, D.,(2001), "Linking improvement models to manufacturing strategies-a methodology for SMEs and other enterprises", International Journal of Production Research., Vol. 39, No 12, pp. 2675-2695.

Barnes, D. (2000), "In search of the source of the stream: the process of formation of manufacturing strategy in small and medium-sized enterprises", Journal of Small Business and Enterprise Development, Vol. 7, No. 3, pp. 261-271.

Barnes, D. (2002a), "The complexities of the manufacturing strategy formation process in practice", International Journal of Operations \& Production Management, Vol. 22, No. 10, pp. 1090-1111.

Barnes, D. (2002b), "The manufacturing strategy formation process in small and medium-sized enterprises", Journal of Small Business and Enterprise Development, Vol. 9, No. 2, pp. 130-149.

Bell, J., Crick, D. and Young, S. (2004), "Small firm internationalisation and business strategy - an exploratory study of 'knowledge-intensive' and 'traditional' manufacturing firms in the UK", International Small Business Journal, Vol. 22, No. 1, pp. 23-56.

Bellamy, L. C. (2009), "Strategy formulation in SMEs: Indications from a longitudinal study", International Journal of Entrepreneurship and Small Business, Vol. 8, No. 4, pp. 534-549.

Cagliano, R., Blackmon, K. and Voss, C. (2001), "Small firms under MICROSCOPE: international differences in production/operations management practices and performance", Integrated Manufacturing Systems, Vol.12, No. 7, pp. 469-482.

Cagliano, R. and Spina, G. (2002), "A comparison of practice-performance models between small manufacturers and subcontractors", International Journal of Operations \& Production Management, Vol. 22, No. 12, pp. 1367-1388.

Carter, S. and Jones-Evans, D. (Eds.) (2006), Enterprise and Small Business: Principles, Practice and Policy, $2^{\text {nd }}$ ed., Financial Times/Prentice Hall, Harlow, UK

Coch, L. and French, Jr., J. P. R. (1948), "Overcoming resistance to change”, Human Relations, Vol. 1, No. 4, pp. 512-532.

Crowe, T. J. and Cheng, C.-C. (1996), "Using quality function deployment in manufacturing strategic planning”, International Journal of Operations \& Production Management, Vol. 16, No. 4, pp. 3548.

Dangayach, G. S. and Deshmukh S. G. (2001), "Manufacturing strategy: Literature review and some issues", International Journal of Operations \& Production Management, Vol. 21, No 7, pp. 884932.

de Wit, R. and Meyer, R. (2010), Strategy: Process, Content, Context, $4^{\text {th }}$ ed., South-Western Cengage Learning. 
European Commission (2005), The new SME definition - User guide and model declaration, Enterprise and Industry Publications (EN NB-60-04-773-EN-C 92-894-7909-4).

European Commission (2007), Putting SMEs First, DG Enterprise and Industry.

Fine, C. H. and Hax, A. C., (1985), "Manufacturing strategy: A methodology and an illustration", Interfaces, No. 15, Nov-Dec, pp. 28-46.

Galbraith, C.S., Rodriguez, C.L. and DeNoble, A.F. (2008), "SME competitive strategy and location behaviour: an exploratory study of high-technology manufacturing", Journal of Small Business Management, Vol. 46, Iss., 2, pp. 183-202.

Gibbons, P. T. and O'Connor, T. (2005), "Influences on Strategic Planning Processes among Irish SMEs", Journal of Small Business Management, Vol. 43, pp. 170-186.

Gilgeous, V. and Gilgeous, M. (1999), "A framework for manufacturing excellence", Integrated Manufacturing Systems, Vol. 10, No. 1, pp. 33-44.

Gilgeous, V. and Gilgeous, M. (2001), "A survey to assess the use of a framework for manufacturing excellence", Integrated Manufacturing Systems, Vol. 12, No. 1, pp. 48-58.

Ghobadian, A. and Gallear, D. (1997), "TQM and organization size", International Journal of Operations \& Production Management, Vol. 17, No. 2, pp. 121-163.

Größler, A. (2007), "A dynamic view on strategic resources and capabilities applied to an example from the manufacturing strategy literature", Journal of Manufacturing Technology Management, Vol. 18 Iss. 3, pp. $250-266$.

Harris, S., Forbes, T. and Fletcher, M. (2000)," Taught and enacted strategic approaches in young enterprises”, International Journal of Entrepreneurial Behaviour and Research, Vol. 6, No. 3, pp. 125-144.

Hayes, R. H. and Wheelwright, S. C. (1984), Restoring our Competitive Edge: Competing Through Manufacturing, John Wiley \& Sons, New York, NY.

Hayes, R. H. and Wheelwright, S. C. (1979), "Link manufacturing process and product life cycles", Harvard Business Review, Vol. 57, No 1, pp. 133-140.

Hill, T. J. (1989), Manufacturing Strategy: Text and Cases, Macmillan, Basingstoke, UK.

Hill, A. and Hill, T. (2009), Manufacturing Operations Strategy, Palgrave Macmillan, $3^{\text {rd }}$ ed., Basingstoke, UK.

Hitt, M. A., Ireland, R. D. and Hoskisson, R. E. (2007), Strategic Management: Competitiveness and Globalization: Concepts \& Cases, $7^{\text {th }}$ ed., Thomson South-Western, Mason, OH.

Hudson, M., Smart, A. and Bourne, M. (2001), "Theory and practice in SME performance measurement systems", International Journal of Operations \& Production Management, Vol. 21, No. 8, pp. 1096-1115.

Jennings, P. and Beaver, G. (1997), "The performance and competitive advantage of small firms: a management perspective", International Small Business Journal, Vol. 15, No. 2, pp. 63-75.

Jia, G. Z. and Bai, M. (2011), "An approach for manufacturing strategy development based on fuzzyQFD”, Computers \& Industrial Engineering, Vol. 60, No. 3, pp. 445-454.

Karacapilidis, N., Adamides, E. and Evangelou, C. (2006), "A computerized knowledge management system for the manufacturing strategy process", Computers in Industry, Vol. 57, No. 2, pp. 178188.

Kim, J. S. and Arnold, P. (1996), "Operationalizing manufacturing strategy: An exploratory study of constructs and linkage", International Journal of Operations \& Production Management, Vol. 16, No. 12, pp. 45-73.

Kiridena, S., Hasan, M. and Kerr, R. (2009), "Exploring deeper structures in manufacturing strategy formation processes: a qualitative inquiry", International Journal of Operations \& Production Management, Vol. 29, No. 4, pp. 386-417.

Laforet, S. and Tann, J. (2006), "Innovative characteristics of small manufacturing firms", Journal of Small Business and Enterprise Development, Vol. 13, Iss. 3, pp. 363 - 380. 
Leong, G. K., Snyder, D. L. and Ward, P. T. (1990) Research in the process and content of manufacturing strategy, Omega, Vol. 18, No. 2, pp. 109-122.

Lim, R. Y. G., Baines, T., Tjahjono, B. and Chandraprakaikul, W. (2006), "Integrated strategic supply chain positioning for SMEs: an empirical study", International Journal of Logistics Management, Vol. 17, No. 2, pp. 260-276.

Lindström, V. (2008), Formulation of Automation Strategy in Manufacturing Systems: Developing a Methodology for Analysing and Choosing Levels of Automation, $\mathrm{PhD}$ dissertation, Department of Product and Production Development, Chalmers University of Technology, Göteborg, Sweden.

Marsden, A. and Forbes, C. (2003)," Strategic management for small and medium-sized enterprises", in Jones $\mathrm{O}$ and Tilley $\mathrm{F}$ (Eds) Competitive advantage in SMEs: Organising for innovation and change, pp 34-53, Wiley, UK.

Marucheck, A., Pannesi, R. and Anderson, C. (1990), "An exploratory study of the manufacturing strategy process in practice", Journal of Operations Management, Vol. 9, Vol. 1, pp. 101-123.

Mills, J., Platts, K. and Gregory, M. (1995), "A framework for the design of manufacturing strategy processes: A contingency approach", International Journal of Operations \& Production Management, Vol. 15, No. 4, pp. 17-49.

Miltenburg, J. (2005), Manufacturing Strategy: How to Formulate and Implement a Winning Plan, $2^{\text {nd }}$ ed., Productivity Press, New York, NY.

O'Regan, N. and Ghobadian, A. (2006), "Perceptions of generic strategies of small and medium sized engineering and electronics manufacturers in the UK: The applicability of the Miles and Snow typology", Journal of Manufacturing Technology Management, Vol. 17 Iss. 5, pp.603 - 620.

Osterwalder, A. and Pigneur, Y. (2010),“ Business Model Generations: a Handbook for Visonaries, Game Changers and Challengers". Own print by Osterwalder, A. and Pigneur, Y.

Papke-Shields, K. E., Malhotra, M. K. and Grover, V. (2006), "Evolution in the strategic manufacturing planning process of organizations", Journal of Operations Management, Vol. 24, No. 5, pp. 421-439.

Persson, I. (1991), "Developing a manufacturing strategy within a capital-investment process - A case study", International Journal of Operations \& Production Management, Vol. 11, No. 3, pp. 32-42.

Pettigrew, A., Whipp, R. and Rosenfeld, R. (1989), "Competitiveness and the management of strategic change processes", in Francis, A. and Tharakan, P. K. M. (Eds.) The Competitiveness of European Industry: Country Policies and Company Strategies, Routledge, London, UK.

Platts, K. W. (1990), Manufacturing Audit in the Context of Strategy Formulation, PhD dissertation, University of Cambridge, Cambridge, UK.

Platts, K. W. (1994), "Characteristics of methodologies for manufacturing strategy formulation", Computer Integrated Manufacturing Systems, Vol. 7, No. 2, pp. 93-99.

Platts, K. W. and Gregory, M. J. (1990), "Manufacturing audit in the process of strategy formulation", International Journal of Operations \& Production Management, Vol. 10, No. 9, pp. 5-26.

Platts, K. and Tan, K. H. (2004), "Strategy visualisation: knowing, understanding, and formulating", Management Decision, Vol. 42, No. 5, pp. 667-676.

Platts, K. W., Mills, J. F., Neely, A. D., Gregory, M. J. and Richards, A. H. (1996), "Evaluating manufacturing strategy formulation processes", International Journal of Production Economics, Vols. 46-47, pp. 233-240.

Platts, K. W., Mills, J. F., Bourne, M. C. S. and Neely, A. D. (1998), "Testing manufacturing strategy formulation processes", International Journal of Production Economics, Nos. 55-56, pp. 517-523.

Pun, K.-F., Chin, K.-S., White, A. S. and Gill, R. (2004), "Determinants of manufacturing strategy formulation: a longitudinal study in Hong Kong", Technovation, Vol. 24, No. 2, pp. 121-137.

Quinn, J. (1978), “Strategic Change; Logical Incrementalism”, Sloan Management Review, Vol. 20, pp. $7-22$. 
Raymond, L. and Croteau, A.-M. (2006), "Enabling the strategic development of SMEs through advanced manufacturing systems: A configurational perspective", Industrial Management \& Data Systems, Vol. 106, Iss. 7, pp.1012 - 1032.

Riis, J. O. and Johansen, J. (2001), "A strategic approach to develop agile manufacturing", in Gunasekaran, A. (Ed.), Agile Manufacturing: The $21^{\text {st }}$ Century Competitive Strategy, Elsevier Science, Oxford, UK, pp. 53-72.

Riis, J. O. and Johansen, J. (2003), "Developing a manufacturing vision”, Production Planning and Control, Vol. 14, No 4, pp. 327-337.

Riis, J. O., Dukovska-Popovska, I. and Johansen, J. (2006), "Participation and dialogue in strategic manufacturing development”, Production Planning and Control, Vol. 17, No. 2, pp. 176-188.

Robinson, Jr., R. B. and Pearce II, J. A. (1984), "Research thrusts in small firm strategic planning", Academy of Management Review, Vol. 9, No. 1, pp. 128-137.

Rytter, N. G., Boer, H. and Koch, C. (2007), "Conceptualizing operations strategy processes", International Journal of Operations \& Production Management, Vol. 27, No. 10, pp. 1093-1114.

Sadler, I. and Gough, R. (2005), "Applying a strategic planning process to several supply chain partners", Journal of Manufacturing Technology Management, Vol. 16, No. 8, pp. 890-908.

Skinner, W. (1969), "Manufacturing - Missing link in corporate strategy", Harvard Business Review, May-June 1969.

Slack, N. (1995), The Manufacturing Advantage: Achieving Competitive Manufacturing Operations, Management Books, Didcot, UK.

Slack, N. and Lewis, M. (2002), Operations Strategy, Prentice Hall, Harlow, UK.

Sum, C.-C., Kow, L. S.-J. and Chen, C.-S. (2004), "A taxonomy of operations strategies of high performing small and medium enterprises in Singapore", International Journal of Operations \& Production Management, Vol. 24, No. 3, pp. 321-345.

Swamidass, P. M, Darlow, N. and Baines, T. (2001), "Evolving forms of manufacturing strategy development: Evidence and implications", International Journal of Operations \& Production Management, Vol. 21, No. 10, pp. 1289-1304.

Säfsten, K. and Winroth, M. (2002), "Analysis of the congruence between manufacturing strategy and production system in SMME”, Computers in Industry, Vol. 49, No. 1, pp. 91-106.

Säfsten, K. and Winroth, M. (2011), "Manufacturing strategies supporting competitiveness in SMMEs", in Proceedings of the 18th International Annual EurOMA conference, 3-6 July 2011, Cambridge, UK.

Verreynne, M.-L. (2006), "Strategy-making process and firm performance in small firms", Journal of Management \& Organization, Vol. 12, pp. 209-222.

Voss, C.A. (1995), "Alternative paradigms for manufacturing strategy", International Journal of Operations \& Production Management, Vol. 15, Iss. 4, pp.5 - 16.

Wheelwright, S. C. (1978), "Reflecting corporate strategy in manufacturing decisions", Business Horizons, Vol. 21, No. 1, pp. 57-66.

Wiesner, R. and Millett, B. (2012), "Strategic approaches in Australian SMEs: deliberate or emergent?", Journal of Management \& Organization, Vol. 18, No. 1, pp. 98-122.

Woods, A. and Joyce, D. (2003), "Owner-managers and the practice of strategic management", International Small Business Journal, Vol. 21, No. 2, pp. 181-195.

Yin, R. K. (2009), Case Study Research: Design and Methods, SAGE, Thousand Oaks, CA.

Yusof, S.M. and Aspinwall, E. (2000), "Total quality management implementation frameworks: comparison and review", Total Quality Management, Vol. 11, No. 3, pp. 281-294.

\section{About the authors}

Malin Löfving is currently a PhD student at Chalmers University of Technology, Gothenburg, Sweden and School of Engineering, Jönköping University, Jönköping, Sweden. Malin's research interests are small- and medium-sized enterprises, 
manufacturing strategy and manufacturing strategy formulation processes. Malin Löfving is the corresponding author and can be contacted at: malin.lofving@jth.hj.se

Kristina Säfsten is an Associate Professor in the Department of Industrial Engineering and Management at School of Engineering, Jönköping University. Her research focuses on manufacturing strategies, ramp-up of production systems, industrialisation and integrated product development. Her publications include books on development and operation of production systems and on efficient product realisation, and papers that have for example appeared in the International Journal of Manufacturing Technology and Management, Journal of Manufacturing Technology Management, International Journal of Technology Intelligence and Planning, International Journal of Production Economics, and Computers in Industry. Mats Winroth holds a position as Associate Professor of operations management at Chalmers University of Technology, Gothenburg, Sweden. His research interests include manufacturing strategies, with a focus on developing the area into covering issues such as automation, SMEs, collaborative company networks, and sustainability. Recent publications have appeared in Journal of Manufacturing Technology Management, Journal of Engineering and Technology Management, International Journal of Manufacturing and Technology Management, and International Journal of Integrated Supply Management. 